4. Dean BJ, Lostis E, Oakley T, Rombach I, Morrey ME, Carr AJ. The risks and benefits of glucocorticoid treatment for tendinopathy: a systematic review of the effects of local glucocorticoid on tendon. Seminars in arthritis and rheumatism. Feb 2014;43(4):570-6. doi:10.1016/j. semarthrit.2013.08.006

5. Friedrichs J, Taubenberger A, Franz CM Muller DJ. Cellular remodelling of individual collagen fibrils visualized by time-lapse AFM. Journal of molecular biology. Sep 21 2007;372(3): 594-607. doi:10.1016/j.jmb.2007.06.078

6. Nestorova R, Rashkov R. Collagen injections Guna MDs in patients with acute periarthritis of the shoulder: clinical and sonographic assessment. 2013:S135-S136.
7. Nguyễn Quanh Quyên, Pham Văn Diêu. Atlas giải phẫu người, tài liệu dịch của tác giả Netter Frank H. NXB Y hoc 2007; 2007.

8. Rincón-Hurtado A $M$, Rocha-Buelvas $A$, López-Cardona A, Martínez JW. Health-related quality of life of patients with rotator cuff injuries, Cofee Triangle, Colombia, 2013. Revista brasileira de ortopedia. May-Jun 2018;53(3):364-372. doi:10.1016/j.rboe.2018.03.018

9. Corrado B, Bonini I, Chirico VA, et al. Ultrasound-guided collagen injections in the treatment of supraspinatus tendinopathy: a case series pilot study. Journal of biological regulators and homeostatic agents. May-Jun 2020;34(3 Suppl. 2):33-39. advances in musculoskeletal diseases and infections - sotimi 2019.

\title{
KẾT QUẢ PHẪU THUÂT ĐIỀU TRỊ UNG THƯ BIỂU MÔ TUYẾN GIÁP THỂ BIÊTT HÓA TẠI BỆNH VIỆN K CƠ SỞ TÂN TRIỀU
}

\section{TÓM TẮT}

Nghiên cứu tiến cứu được tiến hành trên 156 bệnh nhân ung thư tuyến giáp thể biệt hóa được phâuu thuât tại Bệnh viện $K$ cơ sở Tân Triều từ tháng 6/2020 đển tháng 6/2021 nhằm đánh giá kết quả phâu thuât ở nhóm bệnh nhân này. Tỷ lệ cắt toàn bộ tuyến giáp và vét hach cổ lần lướt là $75,6 \%$ và $90,4 \%$. Tỷ lệ di căn hach là $44,0 \%$, hay gặp nhất là nhóm hạch trung tâm $(61,3 \%)$. Thể mô bềnh hoc hay găp nhất là thể nhú (chiếm 92,9\%). Khàn tiếng và hạ canxi máu là hai biến chứng hay gặp nhất (chiếm lẩn lượt là $14,7 \%$ và $16 \%$ ), cao hơn ở nhóm cắt toàn bộ tuyển giáp.

Tư khóa: Ung thư tuyến giáp thể biệt hóa, kết quả phẫu thuật.

\section{SUMMARY \\ SURGICAL OUTCOME OF WELL- DIFFERENTIATED THYROID CANCER AT K HOSPITAL IN TAN TRIEU}

This is a prospective study on 156 cases with welldifferentiated thyroid carcinoma treated by surgery at K Hospital in Tan Trieu from June 2020 to June 2021 to evaluate surgical outcomes in this group of patients. The proportions of total thyroidectomy and lymph node dissection were $75.6 \%$ and $90.4 \%$ respectively. The rate of lymph node metastasis was $44.0 \%$, the most common are group center $(61.3 \%)$ The most common histopathological form is the papillary (92.9\%). Hoarse voice and hypocalcemia were the two most common complications, (accounting for $14.7 \%$ and $16.6 \%$ respectively), in

*Trường Đại học Y dược Thái Nguyên

**Bênh viền $K$

Chịu trách nhiệm chính: Nguyễn Tuấn Sơn

Email: tuanson9999@gmail.com

Ngày nhâan bài: 24.6.2021

Ngày phản biên khoa hoc: 18.8.2021

Ngày duyệt bài: 26.8.2021

\section{Nguyễn Tuấn Sơn*, Hàn Thị Vân Thanh**}

which patients with total thyroidectomy had higher rates.

Keywords: Differentiated thyroid cancer, surgical outcome.

\section{I. ĐĂT VẤN ĐỀ}

Ung thư tuyến giáp (UTTG) đứng đâu trong các ung thư hệ nội tiết, chiếm $90 \%$ và đang có xu hướng ngày một tăng. Theo GLOBOCAN 2018, trên thế giới UTTG đứng hàng thứ 11 trong số các loại ung thư nói chung với tổng số 567.233 ca mắc chiếm tỷ lệ 3,1\%, và 41.071 ca tử vong chiếm tỷ lệ 0,43\%. UTTG đứng hàng thứ 5 trong các loại ung thư ở nữ giới. Tỷ lê mắc chuẩn theo độ tuổi 6.7/100.000 dân, tỷ lệ nữ / nam là 3/1[6]. Tại Việt Nam, UTTG đứng hàng thứ 9 với 5.418 ca mới mắc, 528 ca tử vong mỗi năm, tỷ lê mắc chuẩn theo độ tuổi là 3,52/100.000 dân, đứng thứ 6 trong các loại ung thư ở nữ giới[6].

UTTG thể biệt hóa bao gồm thể nhú và thể nang, chiếm hơn 90\% các trường hợp[7]. Phẫu thuật là phương pháp điều trị chủ đạo trong ung thư tuyến giáp, các phương pháp khác có vai trò bổ trợ. Hiên nay có hai phương pháp phẫu thuât là cắt toàn bộ tuyến giáp và cắt thùy và eo tuyến có thể kèm theo vét hạch cổ tùy trường hợp.

Trong những năm gân đây, tỷ lệ UTTG thể biệt hóa gia tăng nhanh chóng trên toàn thế giới. Việc thực hiện rộng rãi tâm soát ung thư và sự sẵn có của siêu âm và các phương tiện chẩn đoán hỗ trợ khác đã giúp phát hiện được một lương lớn UUTTG ở giai đoan sớm, khối u nhỏ nguy cơ thấp[8]. Phân loai mới TNM của AJCC 2017, trong đó mức tuổi 55 được sử dụng làm mức "cut off" đã thay đổi chẩn đoán giai đoạn so 
với phân loại trước[9]. Vì vậy, điều trị phẫu thuật UTTG thể biệt hóa có nhiều thay đổi. Do đó, chúng tôi thực hiện nghiên cứu này nhằm muc tiêu đánh giá kết quả phẫu thuật điều trị phẩu thuật UTTG thể biệt hóa trong giai đoạn từ tháng 06/2020 đến tháng 06/ 2021.

\section{II. ĐỐI TƯợNG VÀ PHƯƠNG PHÁP NGHIÊN CỨU}

1. Đối tượng nghiên cứu. Nghiên cứu được thực hiện trên 156 bệnh nhân được chẩn đoán ung thư tuyến giáp thể biệt hóa và được điều trị phẩu thuật tại Bệnh viện $K$ từ tháng 06/2020 đến tháng 06/2021.

Tiêu chuẩn lựa chọn bênh nhân. Bênh nhân được chẩn đoán ung thư biểu mô tuyến giáp thể biệt hóa dựa vào đặc điểm lâm sàng và cận lâm sàng; Bệnh nhân được điều trị bằng phẫu thuật lần đầu; Kết quả mô bệnh học sau mổ là ung thư biểu mô tuyến giáp thể biệt hóa.

Tiêu chuẩn loại trừ. Bệnh nhân không đồng ý tham gia nghiên cứu.

\section{Phương pháp nghiên cứu}

- Phương pháp nghiên cứu: Nghiên cứu mô tả

- Các chỉ tiêu nghiên cứu

Đặc điểm khối u giáp bao gồm: vị trí, kích thước, số lượng, mật độ, phân loại TIRADS 2011 được xác định dựa trên kết quả siêu âm, kết quả chọc hút tế bào bằng kim nhỏ (FNA), giải phẫu bệnh sau mổ.

Phương pháp phẫu thuật bao gồm: Cắt thùy + eo tuyến giáp và cắt toàn bộ tuyến giáp. Phẫu thuật vét hạch cổ bao gồm: không vét hạch, vét hạch cổ trung tâm và vét hạch cổ bên. Phương pháp phẫu thuật chỉ định theo phác đồ hiện hành.

\section{Các biến chứng sau mố}

+ Chảy máu: Vùng cổ sưng phồng, dẫn lưu ra nhiều máu đỏ tươi và máu đông, khó thở. Xử trí: Mổ cầm máu.

+ Khàn tiếng: khàn nhẹ, giọng nói thay đổi nhưng vẫn nói được. Có thể khàn tiếng nặng hoặc nhe.

+ Khó thở: phải thở oxy, thở qua ống nội khí quản hay mở khí quản do tổn thương dây thần kinh quặt ngược hoặc do xẹp khí quản.

+ Tể bì, co quắp chân tay: Bệnh nhân tê bì đầu chi, co quắp tay chân. Xét nghiệm nồng độ canxi trong máu giảm (nếu có).

+ Rò dưỡng chấp: Dịch dưỡng chấp màu trắng đục chảy qua dẫn lưu. Nguyên nhân thường do vét hạch cổ làm tổn thương trái ống ngực. Xử trí: Điểu trị nội khoa hoặc phải phẫu thuật đóng đường rò.

+ Nhiểm trùng vết mổ: Bệnh nhân đau nhức vùng mổ, sốt, số lượng bạch cầu tăng, vết mổ nề đỏ, chảy dịch mủ.

3. Xử lý số liệu. Số liệu được xử lý trên phần mềm SPSS 20.0. Thống kê mồ tả gồm tỷ lệ phần trăm, trị số trung bình, độ lệch chuẩn. Đánh giá mối liên quan bằng Fisher Exact test. Mức ý nghĩa thống kê $p<0,05$.

\section{KẾT QUẢ NGHIÊN CứU}

1. Đặc điểm lâm sàng, cận lâm sàng. Độ tuổi trung bình là $46,12 \pm 11,82$, bệnh nhân trẻ tuổi nhất là 16 tuổi, bệnh nhân lớn tuổi nhất là 76 tuổi. Nhóm tuổi $<55$ tuổi chiếm đa số với tỷ lệ $71,2 \%$. Tỷ lệ nư// nam là $6,8 / 1$.

\section{Bảng 1: Đăc điểm khôi u giáp}

\begin{tabular}{|c|c|c|c|}
\hline \multicolumn{2}{|c|}{ Các chỉ số } & Số BN & Tỷ lê (\%) \\
\hline \multirow{3}{*}{ Vị trí } & Thùy phải & 82 & 52,6 \\
\hline & Thùy trái & 67 & 42,9 \\
\hline & Eo giáp & 7 & 4,5 \\
\hline \multirow[t]{2}{*}{ Số lượng } & $1 \mathrm{u}$ & 77 & 49,4 \\
\hline & $\geq 2 \mathrm{u}$ & 79 & 50,6 \\
\hline \multirow{3}{*}{$\begin{array}{l}\text { Kích } \\
\text { thước }\end{array}$} & $\leq 2 \mathrm{~cm}$ & 146 & 93,6 \\
\hline & $2-4 \mathrm{~cm}$ & 9 & 5,8 \\
\hline & $\geq 4 \mathrm{~cm}$ & 1 & 0,6 \\
\hline \multirow{2}{*}{$\begin{array}{l}\text { Phân loaai } \\
\text { TIRADS }\end{array}$} & 4 & 112 & 71,8 \\
\hline & 5 & 44 & 21,2 \\
\hline \multirow{3}{*}{$\begin{array}{l}\text { Kết quả } \\
\text { FNA }\end{array}$} & Lành tính & 7 & 4,5 \\
\hline & Nghi ngờ & 71 & 45,5 \\
\hline & Ung thư & 78 & 50,0 \\
\hline
\end{tabular}

Nhận xét: Trong nghiên cứu của chúng tôi, vị trí u ở thùy phải tuyến giáp chiếm tỷ lệ $52,6 \%$, u ở thùy trái chiếm $42,9 \%$, u ở eo giáp ít gặp chiếm tỳ lệ $4,5 \%$. Trên siêu âm có $50,6 \%$ bệnh nhân có từ $2 u$ trở lên. Phần lớn u có kích thước $\leq 2 \mathrm{~cm}$ chiếm tỷ lệ 93,6\%. Phân loại TIRADS dựa trên siêu âm, phần lớn là TIRADS 4 chiếm $71,8 \%$. Tất cả các bệnh nhân đều được chọc hút tế bào bằng kim nhỏ để chẩn đoán, trong đó phần lớn có kết quả ác tính và nghi ngờ chiếm tỷ lệ lần lượt là $50,0 \%$ và $45,5 \%$. Có 7 bệnh nhân có kết quả lành tính trước mổ, các bệnh nhân này đều có hình ảnh siêu âm nghi ngờ cao, TIRADS 4b, được phẫu thuật và sinh thiết tức thì trong mổ đều cho kết quả carcinoma tuyến giáp.

\section{Kết quả phẫu thuâtt}

Bảng 2: Phương pháp phẫu thuật tuyến giáp và vét hạch cố

\begin{tabular}{|c|c|c|c|}
\hline \multicolumn{2}{|c|}{$\begin{array}{l}\text { Phương pháp } \\
\text { phẫu thuật }\end{array}$} & Số BN & Tổng \\
\hline \multirow{2}{*}{$\begin{array}{c}\text { Cắt } \\
\text { thùy }+ \\
\text { eo giáp }\end{array}$} & $\begin{array}{l}\text { Không vét } \\
\text { hạch }\end{array}$ & $11(28,9 \%)$ & \multirow{2}{*}{$\begin{array}{c}38 \\
(24,4 \%)\end{array}$} \\
\hline & Có vét hạch & $27(71,1 \%)$ & \\
\hline \multirow{2}{*}{$\begin{array}{c}\text { Cắt } \\
\text { toàn bộ } \\
\text { tuyến } \\
\text { giáp }\end{array}$} & $\begin{array}{l}\text { Không vét } \\
\text { hạch }\end{array}$ & $4(3,4 \%)$ & \multirow{2}{*}{$\begin{array}{c}118 \\
(75,6 \%)\end{array}$} \\
\hline & Có vét hạch & $114(96,6 \%)$ & \\
\hline
\end{tabular}


\begin{tabular}{|l|c|} 
Tổng & $\begin{array}{c}156 \\
(100 \%)\end{array}$ \\
\hline
\end{tabular}

Nhận xét: Tỷ lệ bệnh nhân được phẫu thuật cắt toàn bô tuyến giáp chiếm phân lớn với tỷ lệ $75,6 \%$ và bệnh nhân được phẫu thuật cắt thùy eo tuyến giáp chiếm $24,4 \%$.

Tỷ lệ bệnh nhân được vét hạch cổ trong nhóm cắt toàn bộ tuyến giáp cao hơn so với nhóm cắt thùy eo tuyến giáp với tỷ lệ tương ứng là $96,6 \%$ và $71,1 \%$.

Bảng 3: Phân loại vét hạch cổ

\begin{tabular}{|c|c|c|}
\hline Vét hạch cổ & SL & Tỷ lệ(\%) \\
\hline $\begin{array}{c}\text { Chỉ vét hạch cổ nhóm trung } \\
\text { tâm }\end{array}$ & 109 & 77,3 \\
\hline $\begin{array}{c}\text { Vét hạch cố trung tâm và vét } \\
\text { hạch cổ 1 bên }\end{array}$ & 27 & 19,1 \\
\hline $\begin{array}{c}\text { Vét hạch cố trung tâm và vét } \\
\text { hạch cổ 2 bên }\end{array}$ & 5 & 3,5 \\
\hline Tống & $\mathbf{1 4 1}$ & $\mathbf{1 0 0}$ \\
\hline
\end{tabular}

Nhận xét: Tồng số có 141 bệnh nhân được vét hạch cổ, tất cả đều được vét hạch cổ trung tâm. Tỷ lệ vét hạch cổ trung tâm đ̛ơn thuân là $77,3 \%$. Tỷ lệ vét hạch cổ trung tâm và hạch cổ bên là $22,7 \%$, trong đó chủ yếu là vét hạch cổ một bên.

Bảng 4: Kêt quả mô bệnh học

\begin{tabular}{|c|c|c|}
\hline Mô bệ̉nh học & SL & Tỷ lệ (\%) \\
\hline Thể nhú & 145 & 92,9 \\
\hline Thể nhú biến thể nang & 11 & 7,1 \\
\hline Thể nang & 0 & 0 \\
\hline Tống & 156 & 100 \\
\hline
\end{tabular}

Nhận xét: Đa số bệnh nhân có mô bênh học là ung thư tuyến giáp thể nhú $(92,9 \%)$, chỉ $7,1 \%$ là ung thư tuyến giáp thể nhú biến thể nang.

\section{Bảng 5. Di căn hạch cổ}

\begin{tabular}{|c|c|c|c|}
\hline \multicolumn{2}{|c|}{ Kết quả di căn hạch } & $\begin{array}{c}\text { Số } \\
\text { lượng }\end{array}$ & $\begin{array}{c}\text { Tỷ leêe } \\
\text { (\%) }\end{array}$ \\
\hline Vét hạch & Có di căn hạch & 62 & 44 \\
\cline { 2 - 4 } cố & Không di căn hạch & 79 & 56 \\
\hline $\begin{array}{c}\text { Vị trí } \\
\text { hạch di di } \\
\text { căn }\end{array}$ & Nhóm VI & 38 & 61,3 \\
\cline { 2 - 4 } & Hạch cổ bên & 7 & 11,3 \\
\cline { 2 - 4 } & VI và hạch cố bên & 17 & 27,4 \\
\hline
\end{tabular}

Nhânn xét: Trong số 141 bệnh nhân được vét hạch cổ, có 62 bệnh nhân có kết quả giải phẫu bệnh là ung thư tuyến giáp di căn, chiếm $44 \%$.

Tỷ lệ di căn hạch nhóm VI đơn thuần là $61,3 \%$, di căn cả hạch nhóm VI và hạch cổ bên là $27,4 \%$, hiện tượng nhảy cóc chỉ di căn hạch cảnh đơn thuẩn gặp ở 7 bệnh nhân, chiếm $11,3 \%$.

Bảng 6. Các biến chứng sau phẫu thuât

\begin{tabular}{|c|c|c|c|}
\hline $\begin{array}{c}\text { Các biến } \\
\text { chứng sau } \\
\text { phâ̂u thuật }\end{array}$ & $\mathbf{2 4}$ giờ & $\mathbf{7 2}$ giờ & $\mathbf{1}$ tuân \\
\hline Chảy máu & $1(0,6 \%)$ & 0 & 0 \\
\hline
\end{tabular}

\begin{tabular}{|c|c|c|c|}
\hline Khó thơ & $1(0,6 \%)$ & 0 & 0 \\
\hline Khàn tiếng & $22(14,1 \%)$ & $23(14,7 \%)$ & $18(11,6 \%)$ \\
\hline $\begin{array}{c}\text { Tê bì, co quắp } \\
\text { tay chân }\end{array}$ & 19 & 25 & 8 \\
\hline tàn & $(12,2 \%)$ & $(16,0 \%)$ & $(5,2 \%)$ \\
\hline
\end{tabular}

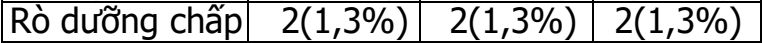

Nhận xét: Biến chứng chảy máu và khó thở ít gặp, chỉ xảy ra trong 24 giờ đầu với tỷ lệ lần lượt là $0,6 \%$ và $0,6 \%$. Khàn tiếng và tê bì tay chân là 2 biến chứng hay gặp nhất, tỷ lệ cao nhất gặp sau 72 giờ lần lượt là $14,7 \%$ và $16 \%$, sau đó giảm dần sau 1 tuần. Biến chứng rò dưỡng chấp gặp ở 2 bệnh nhân chiếm tỷ lệ 1,3\%, tiến triển trong vòng 1 tuần sau đó ổn định.

Bảng 7: Mối liên quan giữa tê bì co rút tay chân và phương pháp phẫu thuật

\begin{tabular}{|c|c|c|c|c|}
\hline \multirow{2}{*}{\multicolumn{2}{|c|}{ Đặc điểm }} & \multicolumn{2}{|c|}{ Tê bì co rút tay chân } & \multirow[b]{2}{*}{ p } \\
\hline & & Có & Không & \\
\hline \multirow{2}{*}{$\begin{array}{l}\text { Phương } \\
\text { pháp } \\
\text { phâ̂u } \\
\text { thuật }\end{array}$} & $\begin{array}{c}\text { Cắt } \\
\text { TBTG }\end{array}$ & $\begin{array}{c}23 \\
(19,5 \%)\end{array}$ & $\begin{array}{c}95 \\
(80,5 \%)\end{array}$ & \multirow[b]{2}{*}{0,038} \\
\hline & $\begin{array}{c}\text { Cắt thùy } \\
\text { và eo } \\
\text { qiáp }\end{array}$ & $\begin{array}{c}2 \\
(5,3 \%)\end{array}$ & $\begin{array}{c}36 \\
(94,7 \%)\end{array}$ & \\
\hline
\end{tabular}

Nhân xét: Tỷ lê tê bì co rút tay chân ở nhóm bệnh nhân cắt TBTG cao hơn so với nhóm bệnh nhân cắt thùy và eo giáp, sự khác biệt có ý nghĩa thống kê $(p<0,05)$.

Bảng 8: Môi liên quan giữa khàn tiêng và phương pháp phẫu thuật

\begin{tabular}{|c|c|c|c|c|}
\hline \multicolumn{2}{|c|}{ Đặc điểm } & \multicolumn{2}{c|}{ Khàn tiếng } & \multirow{2}{*}{ p } \\
\cline { 2 - 4 } & Có & Không & \\
\hline $\begin{array}{c}\text { Phương } \\
\text { pháp } \\
\text { phẩu } \\
\text { thuật }\end{array}$ & Cắt TBTG & 22 & 96 & 0 \\
\cline { 2 - 4 } & $\begin{array}{c}\text { Cắt thùy eo giáp } \\
(18,6 \%)\end{array}$ & $\begin{array}{c}(81,4 \%) \\
(2,6 \%)\end{array}$ & $\begin{array}{c}37 \\
(97,4 \%)\end{array}$ & \\
\hline
\end{tabular}

Nhận xét: Tỷ lệ khàn tiếng ở nhóm bệnh nhân cắt toàn bộ tuyến giáp cao hơn so với nhóm bệnh nhân cắt thùy + eo giáp, sự khác biệt có ý nghĩa thống kê với $p<0,05$.

\section{BÀN LUẬN}

Trong nghiên cứu của chúng tôi, độ tuổi trung bình của các bệnh nhân trong nghiền cứu là 46,12 $\pm 11,82$, bệnh nhân trẻ tuổi nhất là 16 tuổi, bệnh nhân lớn tuổi nhất là 76 tuổi. Nhóm tuổi <55 tuổi chiếm đa số với tỷ lệ 71,2\%. Theo Hoàng Huy Hùng, lứa tuổi hay gặp là 15- 45 tuổi, chiếm tỷ lệ $54,1 \%$, tuổi trung bình là 43,68 , thấp nhất là 13 tuổi, cao nhất là 73 tuổi. Bệnh nhân thuộc nhóm <15 tuổi và > 45 tuổi chiếm $45,9 \%$ trong đó có $2 \%$ thuộc nhóm $<4,8 \%$ [2]. Trong nghiên cứu của chúng tôi, vị trí u ở phùy phải và thùy trái lần lượt là $52,6 \%$ và $42,9 \%$, u ở eo giáp ít gặp chỉ chiểm 4,5\%. Nghiên cứu của Nguyễn Xuân Hậu, u ở thùy phải và thùy trái có 
tỷ lệ như nhau chiếm $44,8 \%$, ít gặp u ở eo giáp chiểm 4,1\%. Tỷ lệ nữ/ nam là 6,8/1 [1]. Hiện nay sử dụng phân loại TIRADS, tổng hợp các đặc tính ác tính của u giáp trên siêu âm. Trong nghiên cứu của chúng tôi phần lớn u giáp TIRADS 4 chiếm $71,8 \%$. Kết quả này tương đương với nghiên cứu của Trần Văn Thông (2014) là 71,1\% u TIRADS 4, 21,1\% u TIRADS 5 [4]. Nghiên cứu của chúng tôi cho kết quả FNA có tỷ lệ ung thư và nghi ngờ lần lượt là $50,0 \%$ và $45,5 \%$, có $4,5 \%$ ung thư tuyến giáp có kết quả FNA lành tính. Tỷ lệ này tương đương với các nghiên cứu trước đó rằng tỷ lệ chẩn đoán dựa vào tế bào học là cao. Nghiên cứu của Nguyễn Xuân Hậu, kểt quả xét nghiệm tế bào học cho thấy $61,2 \%$ trường hợp ác tính, 31,8\% nghi ngờ và $7,1 \%$ lành tính [1].

Tỷ lệ di căn hạch trong UTTG khoảng 2060\%. Nghiên cứu của Mai Thế Vương (2019), tỷ lệ di căn hạch cổ trong UTTG là 35,4\%[5]. Trong nghiên cứu của chúng tôi, tỷ lệ di căn hạch cổ trong UTTG thể biệt hóa là 44,0\%, trong đó tỷ lệ di căn hạch nhóm VI đơn thuần là $61,3 \%$, di căn cả hạch nhóm VI và hạch cổ bên là $27,4 \%$, hiện tượng nhảy cóc chỉ di căn hạch cảnh đơn thuần gặp ở 7 bệnh nhân, chiếm 11,3\%. Có thể thấy kểt quả các nghiên cứu còn dao động, cần thêm các nghiên cứu so sánh trực tiếp khác để làm rõ vấn đề này.

Về mô bệnh học của UTTG, theo nghiên cứu của Nguyễn Xuân Hậu (2019), UTTG thể nhú chiếm đa số với tỷ lệ $99,3 \%, 6,4 \%$ thể nhú biến thể nang, thể nang chiếm 0,7\%[1]. Trong nghiên cứu của chúng tôi, UTTG thể nhú chiếm $92,9 \%$, thể nhú biến thể nang là $7,1 \%$. Kết quả này phù hợp với các nghiên cứu trước đó chỉ ra rằng UTTG thể nhú là thể mô bệnh học hay gặp nhất trong UTTG.

Hạ canxi máu do suy tuyến cận giáp là một biến chứng thường gặp sau phẫu thuật ung thư tuyến giáp. Trong nghiên cứu của chúng tôi, tỷ lệ bệnh nhân hạ canxi máu có biểu hiện tê bì co rút tay chân sau 24 giờ là $12,2 \%$, biểu hiện rõ nhất ở thời điểm 72 giờ với tỳ lệ $16 \%$, sau đó giảm dần ở thời điểm 1 tuần là $5,2 \%$. Tỷ lệ hạ canxi trong nghiên cứu của chúng tôi thấp hơn so với một số nghiên cứu trước đó. Nghiên cứu của Lê Vằn Long với tỷ lệ cũng tại 3 thời điểm trên là $9,54 \%, 22,72 \%$ và $7,27 \%$.[3] Nghiên cứu của Trần Văn Thông biến chứng co rút đầu ngón tay với tỷ lệ sau 24 giờ và 72 giờ lần lượt là $5,71 \%$ và $25,7 \%$.[4] Như vậy, có thể thây tỷ lệ hạ canxi máu sau phẫu thuật đạt cao nhất ở thời điểm 72 giờ sau mổ, sau đó sẽ hồi phục dần.
Tổn thương thần kinh thanh quản quặt ngược là một trong hai biến chứng hay gặp nhất nhất sau phẫu thuật tuyến giáp, bên cạnh suy tuyến cận giáp. Trong nghiên cứu của chúng tôi, tỷ lệ khàn tiếng sau 24 giờ là $14,1 \%$, sau 72 giờ là $14,7 \%$ sau đó giảm dần ở thời điểm 1 tuần là $11,6 \%$. So sánh với các kêt quả nghiên cứu khác như của Lê Văn Long, tỷ lệ khàn tiếng lần lượt là $23,64 \%, 30,45 \%$ và $22,73 \%$ [3], theo Mai Thế Vương tỷ lệ này là $19,9 \%, 32,3 \%$ và $22,4 \%$. [5] Có thể thấy trong nghiên cứu của chúng tôi có tỳ lệ khàn tiếng sau phẫu thuật ít hơn. Điêu này có thể được lý giải do bệnh nhân trong nghiên cứu của chúng tôi được phát hiện sớm, khối u nhỏ, tiên lượng bệnh tốt, và tỷ lệ cắt toàn bộ tuyến giáp và vét hạch cổ trong nghiên cứu của chúng tôi thấp hơn. Trong nghiên cứu của chúng tôi, tỷ lệ hạ canxi và khàn tiếng cao hơn ở nhóm cắt toàn bộ tuyến giáp so với nhóm cắt thùy và eo giáp, sự khác biệt có ý nghĩa thống kê với $\mathrm{p}<0,05$. Điều này là dễ hiểu khi việc phẫu thuật cắt thùy và eo tuyến giáp chỉ thực hiện ở một thùy tuyến giáp, những tuyến cận giáp khỏe mạnh ở đối bên không bị tác động.

\section{KẾT LUẬN}

Độ tuổi trung bình trong nghiên cứu là là $46,12 \pm 11,82$, bệnh nhân trẻ tuổi nhất là 16 tuối, bệnh nhân lớn tuổi nhất là 76 tuổi. Nhóm tuổi < 55 tuổi chiếm đa số với tỷ lệ $71,2 \%$. Tỷ lệ nữ/ nam là $6,8 / 1$. Khối u chủ yểu ở một thùy tuyến giáp, vị trí u ở phùy phải và thùy trái lần lượt là $52,6 \%$ và $42,9 \%$, u ở eo giáp ít gặp chỉ chiếm $4,5 \%$.

Tỷ lệ di căn hạch trong nghiên cứu là 44,0\% (hay gặp nhất là nhóm hạch trung tâm chiếm $61,3 \%)$. UTTG thể nhú là thể mô bệnh học hay gặp nhất trong UTTG chiếm tỷ lệ $92,9 \%$.

Khàn tiếng và tê bì co rút tay chân là hai biến chứng hay gặp nhất sau phẫu thuật, thể hiện rõ sau 72 giờ với tỉ lệ lần lượt là $14,7 \%$ và $16 \%$ sau đó giảm dần.

Tỷ lệ biến chứng tăng lên ở nhóm bệnh nhân cắt toàn bộ tuyến giáp so với nhóm cắt thùy eo giáp, sự khác biệt có ý nghĩa thống kê với p<0,05.

\section{TÀI LIÊU THAM KHẢO}

1. Nguyễn Xuân Hậu (2019), Nghiên cứu giá trị sinh thiết hach cửa trong bệnh ung thư tuyến giáp, Luân án Tiến sĩ y học, Đại học y Hà Nôi.

2. Hoàng Huy Hùng (2016), Đánh giá di căn hach của ung thư biểu mô tuyến giáp,Luận văn Bác sĩ nội trú, Đại học Y Hà Nội.

3. Lề Văn Lơng (2017), Đ̇ánh giá kết quả sớm phẫu thuật ung thư tuyến giáp tại bệnh viện $K$ năm 2017,Luận văn thạc sĩ y học, Đ̇ại học y Hà Nội.

4. Trân Văn Thông (2014), Đánh giá kết quả sớm 
phẫu thuật ung thư tuyến giáp tại Bệnh viện Đại học y Hà Nội, Luận văn thạc sĩ y học, Đại học y Hà Nội.

5. Mai Thế Vương (2019), Nhấn xét đặc điểm lâm sàng, cận lâm sàng và kết quả phẩu thuật của bệnh nhân vi ung thư tuyến giáp thể nhú tại bệnh viện K,Luận văn thạc sĩ y học, Đại học y Hà Nội.

6. Bray F, Ferlay J, Soerjomataram I, et al (2018). "Global cancer statistics 2018: GLOBOCAN estimates of incidence and mortality worldwide for
36 cancers in 185 countries". 68 (6), 394-424.

7. Katoh $H$, Yamashita $K$, Enomoto $T$, et al (2015). "Classification and general considerations of thyroid cancer". 3 (1), 1045.

8. Krajewska j, Kukulska A, OczkoWojciechowska M, et al (2020). "Early Diagnosis of Low-Risk Papillary Thyroid Cancer Results Rather in Overtreatment Than a Better Survival". Front Endocrinol (Lausanne), 11571421.

\title{
KẾT QUẢ PHỤC HỒI CHỨC NĂNG SỚM VỚI RỐI LOẠN NUỐT Ở NGƯỜI BỆNH NHỒI MÁU NÃO CẤP ĐIỀU TRI TẠI KHOA THẦN KINH BÊ̂NH VIỆN BACH MAI
}

\author{
Nguyễn Mạnh Huynh*, Võ Hồng Khôi*, \\ Hoàng Thị Xuân Hương**, Nguyễn Ngọc Hòa***
}

\section{TÓM TẮT}

Đă̆t vấn đề: Đôt quy não là một bênh rất nghiêm trọng và thường để lại hậ̣u quả nặng nề cho bản thân người bênh, gia đình và toàn xã hội nếu không được chăm sóc và điều trị kịp thời. Đây là vấn đề thời sự của tất cả các quốc gia trên toàn thế giới, trong đó có Việt Nam. Rối loạn nuốt sau đột quy xảy ra ở 23-65\% nqười bênh, trong số này, có $37 \%$ phát triển thành viêm phổi hít và gây ra những hậu quả nghiêm trọng. Ngày nay, với sư tiến bô của y hợ, Phục hồi chức năng giai đoạn cấp góp phần phục hồi tiên lượng cho người bệnh Trong đột quy não thì liêt và rối loạn nuốt là dấu hiệu thường gặp và hay đi kèm với nhau. Nếu không được vận động sớm người bệnh dễ mắc teo cơ, cứng khớp, sặc, viêm phổi và suy dinh dưỡng. Xuất phát từ vấn đ̛̣̂̀ trên chúng tôi tiến hành nghiên cứu này. Mục Tiêu: Đánh giá kết quả phục hồi chức năng sớm với rối loạn nuốt ở người bệnh nhî̀i máu não cấp điều trị tại Khoa Thần Kinh Bệnh Viện Bạch Mai. Đối tượng và phương pháp nghiên cửu: P̉ương pháp giả thực nghiẹm không có nhóm chứng (quasiexperiment) trền 96 người bệnh đột quy não cấp (theo tiêu chuẩn chẩn đoán của WHO) có rối loạn nuốt được điều trị tại TT Thần Kinh BV Bạch Mai từ tháng 1 đến tháng 6 năm 2021. Thang điểm GUSS (The Gugging Swallowing Screen) được dùng để đánh giá rối loạn nuốt cho người bệnh. Kết quả và bàn luận: Phần lớn người bê̂nh ở độ tuổi tử 61-70 tuổi (33 người, chiếm $34,4 \%$ ). Sau khi được can thiệp phục hồi chức năng nuốt tất cả 96 người bệnh đều có sự cải thiên về khả năng nuốt tốt hơn so với trước can thiệp (Điểm GUSS tăng từ $11,09 \pm 3,37$ lên $14.31 \pm 1,87$, p $<0,0001)$. Kết luận: Tiến hành áp dụng các bài tập nuốt trên người bệnh đột quỵ não cấp có rối loạn nuốt

*Bênh viện Bạch Mai

**Trường Đai hoc Phenikaa

***Bệnh viện Hữu nghị Đa khoa Nghệ An.

Chịu trách nhiệm chính: Nguyễn Mạnh Huynh

Email: Huynhtkbm@gmail.com

Ngày nhận bài: 16.6.2021

Ngày phản biên khoa hoc: 13.8.2021

Ngày duyệt bài: 13.8.2021 sớm bước đầu đem lại kết quả tốt trong phục hồi khả năng nuốt cho người bệnh.

Tư khóa: Đột quy., tăng huyết áp, rối loạn nuốt, bài tập nuốt.

\section{SUMMARY \\ EVALUATE INITIIAL EFFECTIVENESS OF SWALLOWING REHABILITATION FOR \\ PATIENTS WITH POST-ACUTE STROKE DYSPHAGIA IN NEUROLOGY CENTER OF BACHMAI HOSPITAL}

Background: Stroke is a life-threatening illness. If left without prompt medical treament, stroke resulted in long-term complications for the patient and increasing economic burden. This health condition is the current global issues and Vietnam is not exceptional. Swallowing disorder occurs in $23-65 \%$ of post-stroke patients. Among those, dysphagia lead to aspiration pneumonia in $37 \%$ following severe consequences.Nowadays, due largely to medical advances, rehabilitation in acute stroke patients contribute to the good outcome. In stroke patients, swallowing disorder is common sign and often accompanied by paralysis. Patient who do not receive early physical therapy is prone to develop muscle atrophy, spasticity, aspiration, pneumonia and malnutrition. Objective: to evaluate initial effectiveness of swallowing rehabilitaton for patients with post-acute stroke dysphagia in Neurology Center of Bachmai Hospital. Methods: a quasi-experiment design were conducted in 96 acute onset dysphagia after stroke patients in Bachmai Hospital from January to June 2021. The Gugging Swallowing Screen was used to assess the dysphagia level of participants. Results: The mean ages of participants was 61 to 70 years old group. After attending the swallowing rehabilitation program, participants reported a significantly improvement in swallowing function (GUSS mean score increased from $11,09 \pm 3,37$ to $14,31 \pm 1,87, p<0,0001)$. Conclusion: The swallowing rehabilitation program showed promissing results in improving swallowing function in patients with dysphagia after acute stroke. 